\title{
Environmental nuclear forensics: the need for a new scientific discipline
}

\author{
Georg Steinhauser ${ }^{1}$ (D)
}

Received: 11 February 2019 / Accepted: 13 March 2019 / Published online: 2 May 2019

(C) Springer-Verlag GmbH Germany, part of Springer Nature 2019

Radioecology deals with the presence and fate of radionuclides (radioactive isotopes) in the environment as well as their interactions with the biotic and abiotic environment. The fundamental prerequisite for radioecological studies, therefore, is the detection and quantification of radionuclides in an environmental sample.

Historically, the measurement of environmental radionuclides has come a long way since the discovery of radioactivity. In the early days, the measurement of activity (defined as the number of disintegrations per second with the unit becquerel $(\mathrm{Bq})$; in SI base units, $1 \mathrm{~Bq}=1 \mathrm{~s}^{-1}$ ) had not been a simple task to solve. The reason was that early detection systems based on scintillation or ionization mechanisms (such as $\mathrm{ZnS}(\mathrm{Ag})$ scintillation screens, electroscopes, or early gas ionization detectors) had to be calibrated with a known activity, ideally of the identical radionuclide. This was not always easy to achieve, especially since the (dominant) radionuclide(s) of a sample with multiple radioactive constituents often remained unidentified. Early measurements in the first half of the twentieth century, therefore, were often conducted in comparison with a "universal" comparator, e.g., a uranium standard with a certain mass that was defined as a "uranium unit" (Steinhauser et al. 2016; Steinhauser et al. 2013). For example, the Austrian chemists Carl Auer von Welsbach used a small amount of uranium oxide $\left(\mathrm{U}_{3} \mathrm{O}_{8}\right)$, spread on a metal surface, and defined it as his uranium unit. Of course, his radioanalytical results were not fully comparable with those from other laboratories.

Decades later, during the times of the Cold War, the fallout from atmospheric nuclear weapons tests caused massive global contaminations and required monitoring. The result of this

Responsible editor: Philippe Garrigues

Georg Steinhauser

steinhauser@irs.uni-hannover.de

1 Institute of Radioecology and Radiation Protection, Leibniz Universität Hannover, Herrenhäuser Str. 2,

30419 Hannover, Germany monitoring was often reported as "count rate" (in "counts per second"), as the calibration of a certain radioanalytical device and the accounting of the geometry of a certain measurement position proved to be difficult or at least a bit laborious. Moreover, the fallout consisted of many radionuclides, which made it difficult to account for the individual constituents separately. As an example, I would like to mention my grandfather's efforts in the late 1950s and early 1960s towards the monitoring of the global fallout in Austria. He monitored the presence and deposition of strontium-90 in air filters and rainwater by comparing the count rates of his gas ionization detector over the entire period of observation (Steinhauser 1959; Steinhauser 1965). This allowed the semi-quantitative comparison of the evolution of the contamination over time, but only for the very detector setup that he had been using. Moreover, since no radiochemical separation had been performed in the course of these early environmental monitoring campaigns, the contribution to the total count rate from other fission product radionuclides (e.g., ${ }^{137} \mathrm{Cs},{ }^{106} \mathrm{Ru},{ }^{144} \mathrm{Ce}$ ) could not be accounted for quantitatively. Hence, these measurements often represented gross beta counting. Only for the long-lived radionuclides (e.g., ${ }^{137} \mathrm{Cs}$ and ${ }^{90} \mathrm{Sr}$, with half-lives of 30 and 29 years, respectively), an exact quantification and exposure estimate became possible retrospectively (Gastberger et al. 2000), when modern radioanalytical equipment had become available.

The development and availability of much improved (gamma-) spectroscopic methods, the dawn of radiochemical methods for the separation of the radionuclides, and the availability of certified reference materials allowed going one step beyond. These advances allowed for the monitoring of nuclide-specific activities (instead of count rates), which were quite laborious and time-consuming at first (Liebscher et al. 1961; Schönfeld et al. 1960), but became routine during the second half of the twentieth century. With certain exceptions (e.g., the spectral overlap of ${ }^{239} \mathrm{Pu}$ and ${ }^{240} \mathrm{Pu}$ in alpha spectroscopic measurements due to very similar alpha energies), the "established" set of radioanalytical methods allowed for the identification and quantification of most radionuclides. 
Let me be clear: The exact and accurate determination of an activity concentration of a certain radionuclide in an environmental sample is very valuable. It is what we teach in university laboratories and it is also what the majority of the radioecological submissions to Environmental Science and Pollution Research are currently based upon. In many cases, the sole identification and quantification of a radionuclide's presence in an environmental sample, however, are not enough. We must develop methods and strategies to look deeper into the history and the very nature of a contamination. Anthropogenic radionuclides, for example, have frequently been released from multiple sources, which cause mixing in the environment. For example, plutonium from global weapons fallout had mixed with plutonium released in the course of the Chernobyl nuclear accident. Since two atoms of the same radionuclide, by definition, are indistinguishable from each other, regardless of their source or age, we need a more forensic approach to identify their source.

Most commonly, radionuclide ratios are useful for the identification of the source of a contamination. For example, ${ }^{240} \mathrm{Pu} /{ }^{239} \mathrm{Pu}$ isotopic ratios are highly specific fingerprints of a contamination, not only allowing the distinction of the above-mentioned example of fallout-plutonium from Chernobyl-plutonium but even for the distinction between various reactor types (Cagno et al. 2014). In order to establish this ratio, one can no longer rely on alpha spectrometry, but needs to use mass spectrometry. Sometimes, this ratio includes a "forgotten" radionuclide, such as longlived ${ }^{135} \mathrm{Cs}$, which is the "forgotten" constituent of radiocesium. For decades, a contamination with the prominent gamma emitter ${ }^{137} \mathrm{Cs}$ could not be distinguished from the ubiquitous background. By applying mass spectrometry (Bu et al. 2018) for obtaining the characteristic ${ }^{135} \mathrm{Cs} /{ }^{137} \mathrm{Cs}$ fingerprint of a contamination, this old problem could be solved. Suddenly, it became possible to identify which of the four reactor units of the crippled Fukushima Daiichi nuclear power plant had contaminated which areas in Japan (Zheng et al. 2014). The ${ }^{135} \mathrm{Cs} /{ }^{137} \mathrm{Cs}$ ratio also provided a look into the happenings during the early phase of the Fukushima accident, as it demonstrated a very rapid core meltdown in the reactors (Snow et al. 2016). With sufficiently sensitive methods, ratios of rare transplutonium isotopes such as americium and curium can be established (Yamamoto et al. 2014). There are virtually endless examples of how radionuclide ratios can provide forensic information.

Sometimes, data on single radionuclides (in ratios with natural isotopes) may also be very indicative. The presence of anthropogenic ${ }^{236} \mathrm{U}$ may be a more sensitive indicator for a uranium release from a reactor than hoping to demonstrate such release via minute increases in enriched ${ }^{235} \mathrm{U}$, which also occurs naturally (Schneider et al. 2017). Traces of long-lived ${ }^{60} \mathrm{Fe}$ (a double-(n, $\gamma$ )-activation product from stable ${ }^{58} \mathrm{Fe}$ ) would be an indicator of iron release from a nuclear reactor from a very high neutron flux area (i.e., scaling on the surface of the fuel rods) (Rosenberg et al. 2017).

Sometimes, the chemical speciation of a contaminant can tell the forensic story that we are after. A good example is radioiodine which forms different chemical species under different circumstances, which partly persist for long times in the (marine) environment (Hou et al. 2009), thus allowing their attribution to a source. In certain cases, the chemical environment may be a useful indicator for a deeper look into the history and origin of a species, for example, in the case of radioactive colloids (Walther and Denecke 2013) or particles (Steinhauser 2018).

Lastly, a comprehensive set of environmental nuclear forensic methods will allow the community to better respond to newly emerging contaminants (such as atmospheric radioiodine (Masson et al. 2018)) or unexpected releases, such as the considerable episode of atmospheric ${ }^{106} \mathrm{Ru}$ in Europe in 2017 (Cartlidge 2018). Although not all approaches may be successful, as illustrated by our attempt to identify stable element anomalies within the radioactive ${ }^{106} \mathrm{Ru}$ plume (Zok et al. 2018).

Is environmental nuclear forensics a "new" scientific discipline? Probably not. Various aspects of radioecology exhibit inherently forensic characteristics. For example, radionuclidebased age dating of biological and environmental samples is almost by definition a forensic method that goes back many decades (Anderson et al. 1947; Libby 1946). Similarly, when assessing a fission product contamination, one inevitably had to notice the presence of ${ }^{134} \mathrm{Cs}$ in releases from nuclear reactor accidents (as ${ }^{134} \mathrm{Cs}$ is a typical nuclear reactor nuclide) in contrast to the absence of this radionuclide in nuclear weapons fallout - a simple case of ratio-assisted source attribution. So what is "new" about this discipline? We need a "new" mindset when we approach radioecological research questions. In order for excellent research to stick out from "more of the same," we must shift from reporting data of radionuclide concentrations to the relevance of these concentrations or, even better, to the stories that these radionuclides can tell. And what is the difference to classic nuclear forensics, which is a relatively new scientific discipline by itself? In nuclear forensics, the set of methods strives after providing insight into the age, source, origin, authenticity, and legal background of a nuclear or radioactive material in order to establish knowledge and evidence for a criminal investigation. In environmental nuclear forensics, in contrast, criminological interest is usually not the driving force behind the analyses. In other words, although there is no culprit to be convicted, there is a story to be told about a contamination and its fate in the environment. In the historical development of radioecology, we believe these stories are the next logical challenge that should attract the community's focus. Understanding these stories will almost automatically result in a more holistic understanding of a radioecological research question. 
Presently, our arsenal of forensic methods is far from complete. For example, our methods often fail, when there is only one radionuclide (instead of a pair) present in an environmental sample, so one cannot establish a "story-telling" ratio. However, there are manifold opportunities for developing strategies to solve this problem, e.g., by looking at co-contaminants, stable element/isotope anomalies, chemical speciation, or morphological characteristics that may all be associated with a radioactive contamination. The potential of such opportunities for developing and applying forensic methods in environmental radioactivity studies has not nearly been explored fully. We at Environmental Science and Pollution Research welcome your contributions to this expanding research area. The forensic approach represents a pathway for many years of exciting and valuable cutting-edge radioecological research and related studies in environmental and biological physics and chemistry, radiochemistry, and nuclear sciences.

\section{References}

Anderson EC, Libby WF, Weinhouse S, Reid AF, Kirshenbaum AD, Grosse AV (1947) Radiocarbon from cosmic radiation. Science 105:576-577

Bu W, Ni Y, Steinhauser G, Zheng W, Zheng J, Furuta N (2018) The role of mass spectrometry for radioactive contamination assessment after the Fukushima nuclear accident. J Anal At Spectrom 33:519-546

Cagno S, Hellemans K, Lind OC, Skipperud L, Janssens K, Salbu B (2014) LA-ICP-MS for Pu source identification at Mayak PA, the Urals, Russia. Environ Sci Process Impacts 16:306-312

Cartlidge E (2018) Isotope cloud linked to failed neutrino source. Science 359:729-729

Gastberger M, Steinhäusler F, Gerzabek MH, Hubmer A, Lettner H (2000) ${ }^{90} \mathrm{Sr}$ and ${ }^{137} \mathrm{Cs}$ in environmental samples from Dolon near the Semipalatinsk Nuclear Test Site. Health Phys 79:257-265

Hou X, Hansen V, Aldahan A, Possnert G, Lind OC, Lujaniene G (2009) A review on speciation of iodine-129 in the environmental and biological samples. Anal Chim Acta 632:181-196

Libby WF (1946) Atmospheric helium three and radiocarbon from cosmic radiation. Phys Rev 69:671-672

Liebscher K, Schönfeld T, Schalle A (1961) Concentration of inhaled cerium-144 in pulmonary lymph nodes of human beings. Nature 192:1308

Masson O, Steinhauser G, Wershofen H, Mietelski JW, Fischer HW, Pourcelot L, Saunier O, Bieringer J, Steinkopff T, Hýža M, Møller B, Bowyer TW, Dalaka E, Dalheimer A, de Vismes-Ott A, Eleftheriadis K, Forte M, Gasco Leonarte C, Gorzkiewicz K, Homoki Z, Isajenko K, Karhunen T, Katzlberger C, Kierepko R, Kövendiné Kónyi J, Malá H, Nikolic J, Povinec PP, Rajacic M, Ringer W, Rulík P, Rusconi R, Sáfrány G, Sykora I, Todorović D,
Tschiersch J, Ungar K, Zorko B (2018) Potential source apportionment and meteorological vonditions involved in airborne ${ }^{131} \mathrm{I}$ detections in January/February 2017 in Europe. Environ Sci Technol 52: $8488-8500$

Rosenberg BL, Ball JE, Shozugawa K, Korschinek G, Hori M, Nanba K, Johnson TE, Brandl A, Steinhauser G (2017) Radionuclide pollution inside the Fukushima Daiichi exclusion zone, part 1: depth profiles of radiocesium and strontium-90 in soil. Appl Geochem 85:201-208

Schneider S, Bister S, Christl M, Hori M, Shozugawa K, Synal H-A, Steinhauser G, Walther C (2017) Radionuclide pollution inside the Fukushima Daiichi exclusion zone, part 2: forensic search for the "Forgotten" contaminants Uranium-236 and plutonium. Appl Geochem 85:194-200

Schönfeld T, Liebscher K, Karl F, Friedmann C (1960) Radioactive fission products in lungs. Nature 185:192-193

Snow MS, Snyder DC, Delmore JE (2016) Fukushima Daiichi reactor source term attribution using cesium isotope ratios from contaminated environmental samples. Rapid Commun Mass Spectrom 30:523532

Steinhauser F (1959) Neue Ergebnisse von Messungen der Radioaktivität der Luft in Wien und des Strontium-90 Gehaltes der Niederschläge in Wien und Klagenfurt. Mitteilungen der Österreichischen Sanitätsverwaltung:3 pp.

Steinhauser F (1965) Strontium-90-Ablagerungen aus dem Niederschlag über Europa. Wetter und Leben 17:1-13

Steinhauser G (2018) Anthropogenic radioactive particles in the environment. J Radioanal Nucl Chem 318:1629-1639

Steinhauser G, Adunka R, Hainz D, Löffler G, Musilek A (2016) New forensic insight into Carl Auer von Welsbach's 1910 observation of induced radioactivity: theoretical, experimental and historical approaches. Interdiscip Sci Rev 41:297-318

Steinhauser G, Löffler G, Adunka R (2013) The possible discovery of neutron activation in 1910. J Radioanal Nucl Chem 296:157-163

Walther C, Denecke MA (2013) Actinide colloids and particles of environmental concern. Chem Rev 113:995-1015

Yamamoto M, Sakaguchi A, Ochiai S, Takada T, Hamataka K, Murakami T, Nagao S (2014) Isotopic $\mathrm{Pu}, \mathrm{Am}$ and $\mathrm{Cm}$ signatures in environmental samples contaminated by the Fukushima Dai-ichi Nuclear Power Plant accident. J Environ Radioact 132:31-46

Zheng J, Tagami K, Bu W, Uchida S, Watanabe Y, Kubota Y, Fuma S, Ihara $S$ (2014) Isotopic ratio of ${ }^{135} \mathrm{Cs} /{ }^{137} \mathrm{Cs}$ as a new tracer of radiocesium released from the Fukushima nuclear accident. Environ Sci Technol 48:5433-5438

Zok D, Sterba JH, Steinhauser G (2018) Chemical and radioanalytical investigations of ${ }^{106} \mathrm{Ru}$-containing air filters from Vienna in fall 2017: searching for stable element anomalies. J Radioanal Nucl Chem 318:415-421. https://doi.org/10.1007/s10967-018-6132-6

Publisher's note Springer Nature remains neutral with regard to jurisdictional claims in published maps and institutional affiliations. 